\title{
Utilitarian and hedonic walking: examining the impact of the built environment on walking behavior
}

\author{
Enayat Mirzaei ${ }^{1}$, Reza Kheyroddin ${ }^{1 *}$, Mostafa Behzadfar $^{1}$ and Dominique Mignot ${ }^{2}$
}

\begin{abstract}
Introduction: Most previous studies have mainly focused on utilitarian or recreational walking and discussed their relationship with the built environment. The point is that most of these studies have not been sensitive to the motivation of trips while travel is a complicated behavior and individuals may have different degrees of motivation and utility for a given trip purpose. Accordingly, because of different utilities of travel, it is more likely that the built environment differently affects walking behavior.
\end{abstract}

Purpose: This paper aims to clearly distinguish between utilitarian and hedonic walking and then explores how the built environment influences walking behavior.

Method: Using data collected from 863 respondents in six diverse neighborhoods in Isfahan, Iran, we developed negative binomial models for two types of walking; namely, utilitarian and hedonic walking.

Results: The results reveal some interesting insights: first, both models of walking confirm that neighborhood preferences do not play any important role in explaining walking behavior in our context, inconsistent with previous studies. Second, the objective and perceived built environment factors differently contribute to explaining both types of walking. In this regard, utilitarian walking is affected by mixed land use, residential density, facility accessibility, attractiveness, and walking infrastructure; and hedonic walking is influenced by mixed land use, attractiveness and safety. Third, attitudinal factors and socio-demographic variables also differently appear in the models of walking.

Conclusion: The results confirm that it is essential to be more sensitive to the motivation of trips, and suggest a clear policy implication: the individuals' reactions toward policies intended to increase walking frequency depend partly on the utility for walking.

Keywords: Utilitarian walking, Hedonic walking, Built environment, Negative binomial regression, Iran

\section{Introduction}

Over the past decades, many studies have been conducted to explore how the built environment affects travel behavior. These studies chiefly considered travel as derived demand; that is, travel is a pure means to reach a destination or to participate in an activity $[1,2]$. This consideration seems reasonable because a large portion of trips are utilitarian and thus the researches have tried to model them to manage congested traffic. Nevertheless, there are some trips which are made for

\footnotetext{
* Correspondence: reza_kheyroddin@iust.ac.ir

${ }^{1}$ Faculty of Architecture and Environmental design, Iran University of Science and Technology (IUST), Narmak, Tehran 1684613114, Iran

Full list of author information is available at the end of the article
}

their own sake without any particular destination in mind. These types of trips have intrinsic utility and thus travelers may not necessarily try to minimize the cost and time of travel. Although the share of travel with intrinsic utility is less than that of demand travel, some large-scale surveys show that their portion is not negligible. The 2007-08 French National Travel Survey (FNTS) showed that the destination for the $15 \%$ of trips is not the only important thing. It also shows that fewer than $3 \%$ of trips are "promenade without precise destination" [3]. The 2010 Great Britain National Passenger Survey also found that only $13 \%$ of passengers considered their travel time as wasting time [4]. In Iran, no research has been conducted which specifically measures 
and analyzes the share of travel with different motivations. According to comprehensive transportation plan of Isfahan conducted in 2013, the share of leisure, work and shopping trips were $14.3,10.2$ and $11.5 \%$, respectively [5]. Although the primary motivation of aforementioned trips were not measured, it is likely that these kinds of trips with sizeable portion have different natures and motivations.

In this paper, we are interested to concentrate on walking behavior because increased walking for transport and leisure has a variety of benefits for individuals and society including not only reductions in traffic congestion, air pollution, and emissions [6, 7], but also improvements in public and private health [8-10], social cohesion in neighborhoods and positive sense of place [11, 12]. Walking has long been a subject of interest in different fields. Generally, the studies from transportationrelated planning field has mainly focused on utilitarian walking (e.g. [13-15]) and the studies from public health field has increasingly concentrated on recreational walking and walking trips as a form of physical activity (e.g. [16, 17]). The point is that most of the studies from both fields have not been sensitive to the motivation of trips. Previous studies commonly characterized trips according to several sets of general purposes and there is little or nothing about the needs motivating an activity [18]. Travel is a complicated behavior as individuals may have different degrees of motivation and utility for a given trip purpose. For example, an activity such as shopping may be considered a utilitarian shopping concerned with efficiently purchasing products to achieve a goal of minimal irritation, or a hedonic shopping which emphasizes the pleasure and enjoyment that result from the shopping experience (of course, a single activity may have some of both qualities) [18]. In this study, we used some tactics in our survey to identify two types of trips with specific motivations. We think that distinguishing between trips in terms of motivation and utility helps behavioral scholars, policy-makers and planners to more accurately predict walking behaviors and design specific policies for increasing each type of walking.

Hence, this paper has two main purposes. It aims to clearly distinguish between walking for derived utility and walking for intrinsic utility. We call these types of walking utilitarian walking and hedonic walking, respectively. ${ }^{1}$ After distinguishing between walking trips, this paper contributes to the debate about the relationship between the built environment and different types of walking. We think that it is more likely that different types of walking are affected by various factors such as the built environment, attitudes, residential preferences, socio-demographics, but it is less likely that these factors influence all kinds of walking with similar importance. According to these purposes, this study will also answer the following questions: (1) how can we distinguish between walking trips? (2) What neighborhood characteristics play a significant role in encouraging each type of walking? and are the results consistent for both types of walking?

Finally, it is worth noting that this study contributes to the literature in two ways. Firstly, by improving travel behavior data collection, it incorporates the existence of intrinsic utility of travel into walking behavior models. The second contribution of this research lies in its exploration of differences in the role of built environment in explaining specific walking types.

\section{Literature review}

\subsection{Secondary utility of travel}

Based on traditional travel demand theory, travel is a pure means to reach a destination or to participate in an activity. Nevertheless, there are some trips, which are made for their own sakes. Travel for its own sake has intrinsic utility, while demand travel has extrinsic utility which is simply arriving at specific destinations. This view that travel may have inherent utility dates back to more than three decades ago. Hupkes [19] stated that the travel has not only "derived utility", but a secondary utility which can be called "intrinsic utility". Other studies including Mokhtarian and Salomon [2], Mokhtarian et al. [1], Diana [20] developed and referred to this idea with the expression of "the positive utility of travel", "travel liking", and "primary utility", respectively. It can be said that the intrinsic utility is in contradiction with the microeconomics theory which assumed that travel is a disutility to be minimized. The studies conducted regarding travel time valuation showed that a sizeable number of travelers think of a nonzero ideal travel time (e.g. $[21,22])$.

As for the identification of individuals' utility for travel, Mokhtarian and Salomon [2] described three aspects of utility for travel: "the utility of activities conducted at the destination", "the utility of activities that can be conducted while traveling", and "the utility of activity of traveling itself". The first aspect is the utility of arriving at a destination, which is the traditional derived demand assumption for travel [1], and the second aspect is complementary activities that could also take place without traveling such as reading, thinking or enjoying scenery [18]. The final aspect is a consequence of intrinsic utility of travel itself. For instance, the sensation of speed, movement through and exposure to the environment, and the scene beauty or other attractions of a route are some manifestations of travel for itself [2].

As for measuring the utilities of travel, particularly intrinsic utility, over the past 15 years, a growing number of studies from different perspectives have been sensitive to more understanding of secondary utility for travel. 
Mokhtarian et al. [1] used travel liking to directly measure feeling about traveling. Páez and Whalen [23] considered individuals' desire for decreasing or increasing daily commuting. Moreover, several studies used subjective value of the time spent traveling from wasting to useful time $[14,22,24-26]$ and some others took account of stressed and relaxed level of traveler [24] and travel happiness of traveler with different modes of transport [27]. Further, several researchers used the measure of satisfaction with travel [28, 29]. Diana [20], considering all aspects, proposed several dimensions of travel which are needed to be inquired about. These dimensions are "the presence of implicit intrinsic motivation, the subjective evaluation of trip-related feelings, the desired trip length, and the performances of the transportation mode(s)". Previous researches have mainly used these dimensions as general attitudes of individuals towards traveling, and then examined their relationship with the built environment.

In expanding the subject, Mokhtarian et al. [18] suggested obtaining relevant information about each trip for each person, instead of general attitudes, to reduce the likely measurement errors. They also propose several tactics to clearly distinguish between trips in terms of their utility. The first tactic is to add "Just because I wanted/needed to" to the predefined list of trip purposes. In addition, they propose some questions relating "trip generation", "destination choice" and "route choice" for each trip. In this regard, if individuals satisfactorily prefer to perform an activity without traveling (if possible) and/or to perform it in the nearest place and/or to reach the destination in the fastest practical route, that trip is more likely to be a utilitarian trip. The subjective evaluation of time spent traveling from wasting to well-spent time and teleportation test [30] are other suggestions for distinguishing between different types of travel as well. The next section reviews the literature regarding the empirical relationship between the built environment and different types of walking.

\subsection{Walking behavior and the built environment}

From theoretical standpoint and based on travel demand theory, since travel cost can be influenced by the features of the built environment, utilitarian travel behavior can be affected by the built environment. Travel cost generally includes time, out-of-pocket monetary expenditures and psychological effects such as aesthetics and comfort [31]. For hedonic travel, individuals necessarily have no incentive to minimize the time and out-of-pocket monetary expenditures. Thus, it is likely that the built environment characteristics contribute to explaining hedonic travel through its influence on psychological effects. In this subject, several studies emphasize distinguishing between travel for utilitarian purposes (e.g. walking to work or non-working destination etc.) and travel for recreational purposes such as strolling [32-35]. In recent decades, numerous studies have been published on walking behavior in developing and developed countries.

In this regard, some studies used objective factors of the built environment (e.g. [36-39]) and some others used subjective factors (e.g. [17, 40-45]) to explore the relationship between the built environment and walking activity pattern. Further, there are studies which simultaneously considered objective and subjective characteristics of the built environment $[46,47]$. The former groups that considered objective variables mainly suggested that density, mixed land use, street connectivity, outdoor seating and pedestrian-oriented designs encourage walking trips. Christiansen et al. [35] analyzed the relationship between transport-related walking and objective measures of the built environment based on data obtained from 14 cities across 10 countries worldwide. They also found positive associations of walking for transport with land use mix, residential density, intersection density, and the number of parks. The studies which used perceived measures of the built environment showed that safety from crime [40], fear [46], perception of traffic [40, 43], attractiveness and perceived people out and about within neighborhood [44] are associated with walking.

Specifically in developing country, Munshi [48] from India showed that balanced and mixed land use had a very strong influence and, access to destination and commute distance had a strong impact on walking. Nevertheless, they reported that density and design had a weak association with walking. The studies conducted in China context confirmed that pedestrian or cyclist friendly environment (a mixed use and human scale environment whose commercial and recreational services are easily accessible on foot or by bicycle) encouraged residents to use non-motorized modes, and they suggest that land use planning and urban design can effectively influence people's mobility demand and travel behavior $[49,50]$. In Iran, Etminani-Ghasrodashti and Ardeshiri [51] found that residential and job density, mixed land use, street density and internal connectivity are significantly associated with non-motorized modes for work trips. They [52] showed that non-work trips by nonmotorized modes are influenced by lifestyle, travel attitudes, social cohesion and density, but the effect of lifestyle is stronger than other mentioned factors.

Despite utilitarian walking, the contribution of the built environment in explaining non-utilitarian walking is still not well explored. However, some studies have revealed valuable insights into some types of walking including walking for recreation or walking as a form of physical activity. For example, Handy [53] concluded that some built environment factors play a more 
important role in walking to a destination than strolling. Cao et al. [44] found that perceptions of neighborhood characteristics including walking safety, ample shade, low traffic, and people on the street affect the frequency of strolling. They also found that the number of business types within walking distance, not living on a cul-de-sac, and aesthetic qualities of neighborhood encourage undirected walking/biking. Inoue et al., [72] in their study conducted in Japan found no significant relationship between safety from crime and walking for recreational walking. By reviewing 42 walking studies, Saelens and Handy [34] showed that recreational walking has strong associations with pedestrian infrastructure, aesthetics, safety, and mixed land use, while they found that there is little or no evidence for relationships between recreational walking and some built environment factors including density, distance to destinations, network connectivity, parks, open space, etc. Sugiyama et al. [54] examined associations between perceived environmental attributes and three outcomes of recreational walking (walk or not, how often, and how long), using data collected from 12 developing and developed countries. They found that seven perceived attributes including residential density, land use mix, connectivity, aesthetics, safety from crime, few cul-de-sacs, proximity to parks were (either linearly or curvilinearly) associated with at least one of three walking outcomes. Three others including infrastructure and safety, safety from traffic, no major barriers, were not associated with any of the walking outcomes. In addition, they indicated that their results confirmed findings from prior single-country studies.

In this line of research, the present study aims to distinguish between walking "just" for arriving at particular destinations and hedonic walking; and subsequently investigates the relationships between the perceived factors of the built environment and different types of walking. Moreover, it takes into consideration residential preferences, socio-demographic characteristics and attitudes of individuals towards travel.

\section{Methodology}

\subsection{Data and study area}

The data used in this study came from a survey in 2015-2016 from six neighborhoods in the north of Isfahan, Iran. Isfahan is a large urban region (with the population of more than 3.5 million and an area of 8.3 thousand $\mathrm{km} 2$ ) in the center of Iran, which includes 36 adjacent small, medium and large cities. Isfahan, as the central city of urban region, has a population of 1.8 million, 534,256 households and an area of $482 \mathrm{~km} 2$ [55]. We selected six neighborhoods in the north of Isfahan City for some reasons. Six neighborhoods as representatives of the all urban regions were not sufficient because social characteristics and urban structures within the urban region are very different and complicated to be measured. More importantly, we aimed to analyze the role of some limited dimensions of the built environment such as density, diversity and design. Thus, it was necessary to control some other factors (such as distance from city center and sub-center, traffic congestion, air pollution, microclimate variance, cultural norms etc.) which were out of scope in this study. The north of Isfahan allowed us to select the case studies with different density, diversity and design characteristics but similar characteristics in terms of mentioned control factors. Finally, the northern region of Isfahan has experienced a rapid development during the past decades and needs appropriate strategies for its future development.

On the whole, sample selection is a crucial stage in the built environment- travel behavior research subject. In previous relevant studies, samples were generally chosen based on several factors purposively. For example, Cao et al. [32] selected 6 neighborhoods in Austin, TX area based on their development era. Cao et al. [43, 44] selected 8 neighborhoods based on neighborhood type, size of metropolitan area, and region of the state. Pan et al. [50] chose four representative neighborhoods from the inner and outer city of Shanghai, China based on the time-periods of their development. In the present study, the case studies were systematically selected to vary on the "3Ds" of the built environment; that is, density, diversity, and design. In selection of case studies, we classified potential neighborhoods located in the northern region of Isfahan into six clusters based on the mentioned criteria and finally chose six representative neighborhoods according to the clusters and their location relative to main arterial of the region. According to "2012 Detailed Plan", there were 39 neighborhoods with various urban forms from organic urban form to modern urban form in the north of Isfahan. The neighborhoods with organic urban form are traditional neighborhoods of Isfahan. These neighborhoods are characterized by non-geometric structure, curved and narrow pattern of street, high cul-de-sac density, large block size, high residential density, and large building plots with low height. The second category of neighborhoods surrounds the traditional neighborhoods. Compared to traditional neighborhoods, they are characterized by more regular streets, lower cul-de-sac density, more buildings with medium heights and similar residential density. The neighborhoods with modern urban form are prevailed over the region and have been formed based on official development plans during past decades. They are described by regular and grid patterns of streets, high buildings and residential density, low cul-de-sac density and a few vacant plots. In addition to previous neighborhoods, there are several neighborhoods designed based on the principles of the modern urban form but are not yet 
fully developed. They mainly have low residential density and diversity. Further, they have a considerable number of vacant plots, which, somehow, contribute to disqualify the urban environment of these neighborhoods [56]. The neighborhoods in this study can be classified into three built environment types: Organic type (O1 and O2), SemiModern type (SM1 and SM2) and Modern type (M1 and M2). Physical attributes of the neighborhoods and the region are shown in Table 3 and confirms that there is enough variation between case studies. Figure 1 shows the location and structure of the neighborhoods in the metropolitan part of Isfahan.

Selecting participants living in six different neighborhoods maximizes variation of the built environment factors and socio-demographics, and allows us to much better examine the influence of the built environment on travel-related behaviors. Hence, we aggregate all data collected from six types of neighborhoods and do not analyze walking behavior for individual neighborhoods. After selecting appropriate neighborhoods, the data used in this study were collected by a vast face to face interview and questionnaire relating to socio-economic characteristics, travel attitudes, residential preferences, and subjective measures of the built environment and walking behavior. Indeed, according to the population size of the neighborhoods (7258 households), 863 respondents randomly contributed in the survey. In the survey, a family member, as representatives of the households, reported only his/her own mobility behavior. Table 1 displays some key socio-demographic characteristics of the respondents.

\subsection{Definition of dependent and independent variables 3.2.1 Frequency of utilitarian walking and hedonic walking}

In this study, frequencies of home-based utilitarian and hedonic walking have been modeled as the travel outcomes. To measure frequency of utilitarian walking trips, we specified four non-work destinations (mosques and civic buildings, service providers, stores, and children schools) and asked respondents to report how often they use walking "just" to reach the destinations in a typical month. We stressed that for these trips, walking is mainly performed to reach the nearest places through the shortest practical routes. Since work trips are different from non-work trips in terms of flexibility and discretionary nature, in this study, we excluded work trips to avoid potential biased results. To measure frequency of hedonic walking, we asked respondents to report how often they make walking for each of these activities in a typical month: "just for the fun of it", "just for relaxing", "just for being with friend(s)", "just for

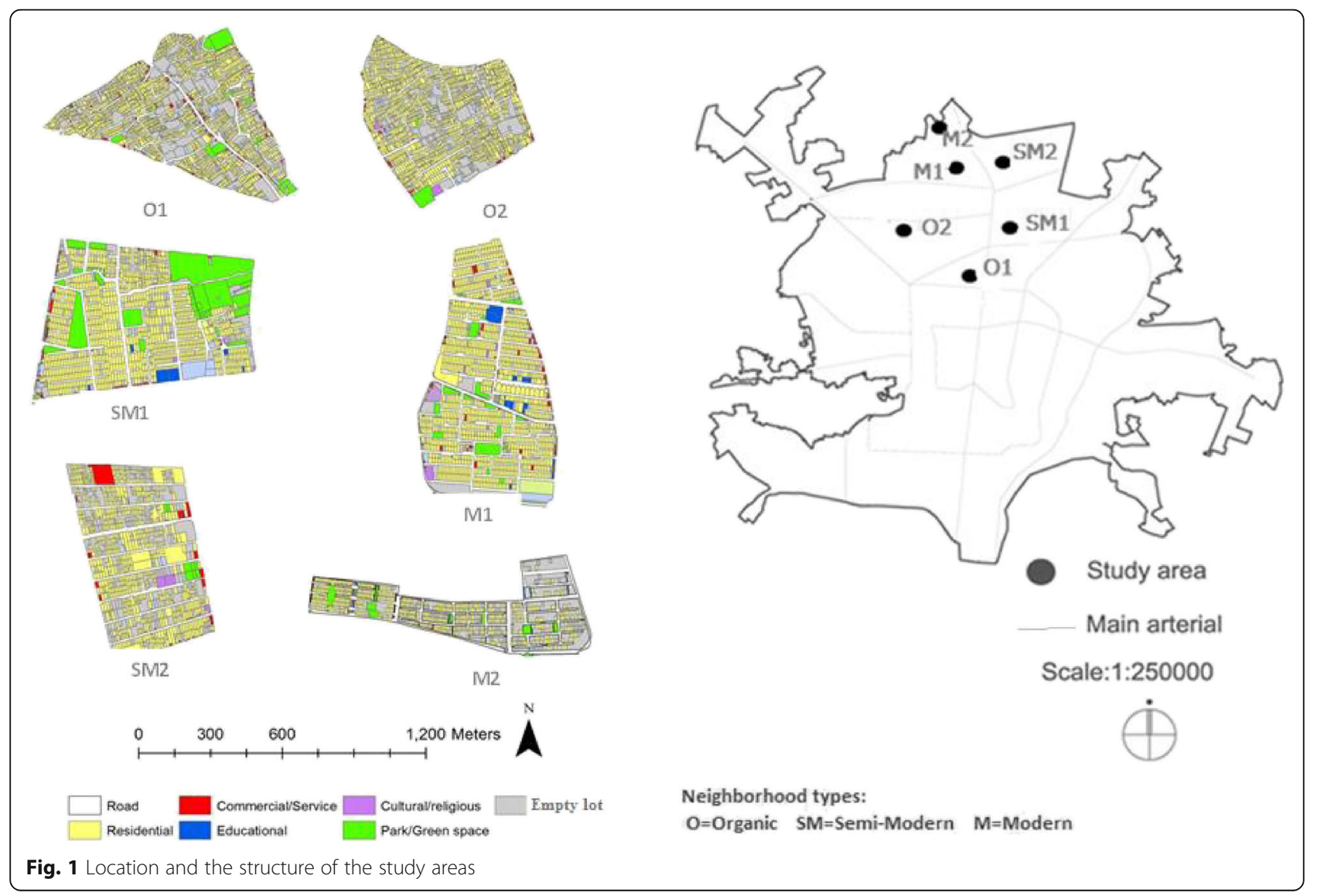


Table 1 Population and sample socio-demographic characteristics $(n=863)$

\begin{tabular}{|c|c|c|c|c|c|c|}
\hline \multirow[t]{2}{*}{ Socio-demographic measures } & \multirow[b]{2}{*}{01} & \multirow[b]{2}{*}{$\mathrm{O} 2$} & \multicolumn{4}{|c|}{ Neighborhood $^{a}$} \\
\hline & & & SM1 & $\mathrm{SM} 2$ & M1 & M2 \\
\hline \multicolumn{7}{|c|}{ Neighborhood population characteristics - 2011 census } \\
\hline Number of household & 1601 & 1100 & 953 & 806 & 2153 & 645 \\
\hline Percentage of male & 53 & 52 & 49 & 55 & 48 & 53 \\
\hline Median age & 44 & 42 & 38 & 42 & 41 & 36 \\
\hline Average household size & 3.21 & 3.8 & 2.9 & 3.3 & 3.7 & 2.8 \\
\hline \multicolumn{7}{|l|}{ Survey respondent characteristics } \\
\hline Number of sample & 193 & 114 & 112 & 94 & 268 & 82 \\
\hline Percentage of male & 48 & 57 & 54 & 49 & 52 & 61 \\
\hline Median age & 42 & 46 & 31 & 35 & 45 & 38 \\
\hline Average household auto ownership & 0.92 & 0.97 & 0.9 & 0.86 & 0.98 & 1.1 \\
\hline Average household size & 3.6 & 3.7 & 3.2 & 3.4 & 3.5 & 3.2 \\
\hline Mean monthly income of household (\$) & 412 & 450 & 520 & 436 & 600 & 430 \\
\hline
\end{tabular}

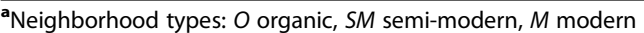

being alone". This type of walking is not necessarily performed to reach a desired destination. It is the portion of travel that is prompted by the second and third aspects of the utility for travel $[1,2]$. For these cases, walking is often a leisure activity itself and is not conducted to reach a leisure activity. Additionally, individuals may choose an alternative with a higher cost, time or longer distance rather than other economical alternatives. It is worth noting that in addition to the explanatory note in the questionnaire, we tried to make a face-to-face interview with respondents to clarify differences between utilitarian and hedonic walking. It is noted that respondents reported completely utilitarian and hedonic trips and the trips with both components of motivation were excluded during the interview (Table 2).

Table 2 Monthly walking trips statistics in the sample $(n=863)$

\begin{tabular}{lll}
\hline Variables & Mean & Std. deviation \\
\hline $\begin{array}{l}\text { Utilitarian walking } \\
\begin{array}{l}\text { No. of trips to mosque and } \\
\text { civic building }\end{array}\end{array}$ & 2.15 & 2.86 \\
$\begin{array}{l}\text { No. of trips to service provider } \\
\text { (e.g. banks, post office) }\end{array}$ & 1.81 & 2.51 \\
$\begin{array}{l}\text { No. of trips to store } \\
\text { No. of trips to children school }\end{array}$ & 5.35 & 4.31 \\
No. of total utilitarian walking & 0.71 & 2.03 \\
Hedonic walking & 10.02 & 8.92 \\
No. of trips just for the fun of it & 0.36 & 0.67 \\
No. of trips just for relaxing & 1.36 & 1.03 \\
No. of trips just for being & 0.43 & 0.69 \\
with friend(s) & & \\
No. of trips just for being alone & 0.81 & 0.98 \\
No. of total hedonic walking & 2.97 & 1.96 \\
\hline
\end{tabular}

\subsubsection{Objective measures of the built environment}

The objective measures of the built environment in the neighborhood level were measured by diversity, residential density, street density, cul-de-sac density and density of bus route. These variables were calculated based on the detailed plan of Isfahan using ArcGIS 10.2 (Revision of detailed plan, 2012). Residential density characterizes the compactness and sprawl level of activities. Entropy index represents the balance of different land use types across the neighborhoods and measures accessibility to various destinations. Road and cul-de-sac density characterize the level of permeability within neighborhoods. Density of bus routes represents the accessibility to transit [57]. Following the literature, these variables are most commonly associated with walking behavior, and we calculated them as follows: residential density is calculated as the number of residents per each hectare of land, diversity of built environment is measured by entropy index, according to this equation:

$$
E I i=-\left(\sum_{j=1}^{j} P j \cdot \ln P j\right) \cdot \frac{1}{\ln j}
$$

In this equation, $\mathrm{Pj}$ refers to the ratio of each land use in the neighborhood and $j$ is the sum of various kinds of land uses (Etminani-Ghasrodashti and Ardeshiri, [51]). Street density is calculated by dividing the number of linear miles of street per square mile of land, and cul-de-sacs density is calculated as the number of culde-sacs divided by square mile of land (Table 3 ).

\subsubsection{Perceived measures of the built environment and residential preferences}

We used 15 statements to measure different dimensions of the built environment and residential preferences in 
Table 3 The built environment attributes of six study areas and the northern region of Isfahan

\begin{tabular}{|c|c|c|c|c|c|c|c|c|}
\hline \multirow{2}{*}{$\begin{array}{l}\text { Built environment } \\
\text { measures }\end{array}$} & \multicolumn{6}{|c|}{ Sample } & \multicolumn{2}{|c|}{ Region } \\
\hline & 01 & $\mathrm{O} 2$ & SM1 & SM2 & M1 & M2 & Mean & SD \\
\hline Residential density & 132 & 115 & 57.32 & 90 & 160 & 73.45 & 102 & 27 \\
\hline Entropy index & 0.51 & 0.40 & 0.28 & 0.35 & 0.67 & 0.30 & 0.39 & 0.12 \\
\hline Street density & 70.1 & 45.4 & 42.7 & 24.6 & 50.36 & 48.9 & 41 & 12 \\
\hline Cul-de-sac density & 623.5 & 492 & 300 & 250 & 95.8 & 18.19 & 284 & 240 \\
\hline Density of bus route & 7.2 & 10.1 & 12.15 & 5.3 & 8.487 & 3.8 & 11.43 & 10.46 \\
\hline
\end{tabular}

our survey. Firstly, respondents were asked to indicate how true the 15 statements are for their neighborhoods, on a 4-point ordinal scale from "not at all true" to "entirely true". The responses reflected the perception of individuals regarding their neighborhood design. Then, to take account of residential preferences issue, respondents were asked to indicate the importance of the same 15 statements if they were looking for a new neighborhood to live (even without any intention for moving), on a four-point ordinal scale from "not at all important" to "extremely important". These responses reflected what they want. Since some of these statements are relating to similar dimensions of the built environment and residential preferences, they were considered together and then they were factor analyzed (principal components analysis, Oblimin with Kaiser Normalization, 59.6\% variance explained, $\mathrm{KMO}=0.71$ ) into five main factors: facility accessibility, safety, attractiveness, walking infrastructure, and socializing (see Table 4). ${ }^{2}$

Table 4 Key variables loading on neighborhood perception and residential preference factors

\begin{tabular}{|c|c|}
\hline Factors & Statements and loadings ${ }^{\mathrm{a}}$ \\
\hline Facility accessibility & $\begin{array}{l}\text { Easy access to other facilities including } \\
\text { public transportation, places for physical } \\
\text { activities, green space,etc. (0.623); Easy } \\
\text { access to a regional shopping mall } \\
(0.514) ; \text { shopping areas within walking } \\
\text { distances }(0.479)\end{array}$ \\
\hline Safety & $\begin{array}{l}\text { Quiet neighborhood }(0.736) \text {; good street } \\
\text { lighting at night }(0.725) \text {; High volume } \\
\text { of car traffic }(-0.469) \text {; High speed of cars } \\
\text { on neighborhood streets }(-0.381) \text {; low } \\
\text { crime rate within neighborhood }(0.358)\end{array}$ \\
\hline Attractiveness & $\begin{array}{l}\text { looking at houses when walking (0.720); } \\
\text { Good sidewalks throughout the } \\
\text { neighborhood ( } 0.636) \text {; Attractive } \\
\text { appearance of neighborhood ( } 0.547)\end{array}$ \\
\hline Walking infrastructure & $\begin{array}{l}\text { parks and open spaces nearby }(0.801) \text {; } \\
\text { good sidewalks throughout the } \\
\text { neighborhood }(0.732) ; \text { good street } \\
\text { lighting at night }(0.399)\end{array}$ \\
\hline Socializing & $\begin{array}{l}\text { lots of people out and about within the } \\
\text { neighborhood }(0.688) \text {; Perception that } \\
\text { neighborhood is friendly/clean }(0.517) \text {; } \\
\text { lots of interactions among neighbors } \\
(0.437)\end{array}$ \\
\hline
\end{tabular}

${ }^{\mathrm{a}}$ Factor loadings are presented in parentheses
According to previous sections, we measured the built environment characteristics at both levels: individual and neighborhood. Since the perception of individuals may be partly affected by objective characteristics of the neighborhoods, we tried to analyze how these types of variables are correlated. The results of correlational analysis are shown in Table 5. Entropy index is weakly correlated with facility accessibility and safety and moderately correlated with attractiveness; residential density has a weak positive with socializing; and cul-de-sac density has a very weak positive associations with safety and socializing. Indeed, street density has a very weak negative relationships with safety and socializing. It is likely that presence of more roads encourages driving and decreases safety and interaction between people.

\subsubsection{Other explanatory variables}

Attitudinal and socio-demographic characteristics are other explanatory variables in the present study. Travel attitude statements are generally regarding people's travel likes, dislikes, individuals' opinions about environmental issues, their sense about travel freedom and travel stress, car dependency, travel minimizing etc. (see $[1,43,44,58])$.To measure travel attitudes, respondents were asked to indicate whether they agreed or disagreed with 13 statements on a 5-point Likert scale from "strongly disagree" to "strongly agree". Using factor

Table 5 Correlational analysis between objective and perceived measures of the built environment

\begin{tabular}{|c|c|c|c|c|c|}
\hline & \multicolumn{5}{|c|}{ Perceived measures of the built environment } \\
\hline & $\begin{array}{l}\text { Facility } \\
\text { accessibility }\end{array}$ & Safety & Attractiveness & $\begin{array}{l}\text { Walking } \\
\text { infrastructure }\end{array}$ & Socializing \\
\hline \multicolumn{6}{|c|}{ Objective measures of the built environment } \\
\hline $\begin{array}{l}\text { Entropy } \\
\text { index }\end{array}$ & $0.254^{* *}$ & *0.125 & ${ }^{*} 0.342$ & & \\
\hline $\begin{array}{l}\text { Residential } \\
\text { density }\end{array}$ & & & & & $0.130^{*}$ \\
\hline $\begin{array}{l}\text { Street } \\
\text { density }\end{array}$ & & $-0.011^{*}$ & & & \\
\hline $\begin{array}{l}\text { Cul-de-sac } \\
\text { density }\end{array}$ & & $0.028^{*}$ & & & $0.001^{*}$ \\
\hline $\begin{array}{l}\text { Density of } \\
\text { bus route }\end{array}$ & & & & & \\
\hline
\end{tabular}


analysis (principal components analysis, Oblimin with Kaiser Normalization, $58.6 \%$ variance explained, $\mathrm{KMO}=$ $0.75)$, Travel attitude statements were extracted into four factors: pro-walking, car dependent, travel minimizing, and travel stress (see Table 6).

Final group of explanatory variables is sociodemographic characteristics. These variables include gender, age, employment status, household auto ownership, monthly household income, household size, and educational background. Many studies have used these variables as controlling variables and found that they have significant associations with travel behavior.

Individuals' attitudes may be related to their preferences for some factors in the neighborhoods. We tested these relations using correlational analysis, and the results show that individuals, who are pro-walking, have preferences for facility accessibility, safety and walking infrastructure. As for other factors, travel minimizing has a very weak positive associations with safety and weak association walking infrastructure, and travel stress is moderately related to facility accessibility. It is noted that car dependent attitude has no significant association with residential preference factors (Table 7).

\section{Results}

\subsection{Distribution of dependent and explanatory variables} across the neighborhoods

A comparison between independent and dependent variables can be seen in Table 8. The ANOVA of the data demonstrates that the means of utilitarian and hedonic walking trips frequency are significantly different between the neighborhoods. In addition, all objective measures of the built environment and attitude factors significantly differ across six neighborhoods. As for perceived and preferred neighborhood design characteristics,

Table 6 Key variables loading on travel attitude factors

\begin{tabular}{|c|c|}
\hline Factors & Statements and loadings ${ }^{a}$ \\
\hline Pro- walking & $\begin{array}{l}\text { Walking generally wastes time }(-0.635) \text {; I prefer } \\
\text { to walk rather than drive whenever possible } \\
(0.536) \text {; I like walking }(0.453)\end{array}$ \\
\hline Car Dependent & $\begin{array}{l}\text { I need a car to do many of the things I like } \\
\text { to do }(0.617) \text {; we would like to own at least } \\
\text { one more car }(0.475) \text {; traveling by car is } \\
\text { safer overall than walking }(0.470) \text {; I like } \\
\text { driving (0.364) }\end{array}$ \\
\hline Travel Minimizing & $\begin{array}{l}\text { When I need to buy something, I usually } \\
\text { prefer to get it at the closest store possible } \\
(0.731) ; \text { I often use the telephone or the } \\
\text { Internet to avoid having to travel somewhere } \\
(0.638) ; \text { The only good thing about traveling is } \\
\text { arriving at destination }(0.486) \text {; }\end{array}$ \\
\hline Travel stress & $\begin{array}{l}\text { I like traveling alone }(-0.652) \text {; traveling makes } \\
\text { me nervous }(0.482) \text { Traveling is generally tiring } \\
\text { for me }(0.369)\end{array}$ \\
\hline
\end{tabular}

${ }^{\mathrm{a}}$ Factor loadings are presented in parentheses
Table 7 Correlational analysis between attitudinal and residential preferences factors

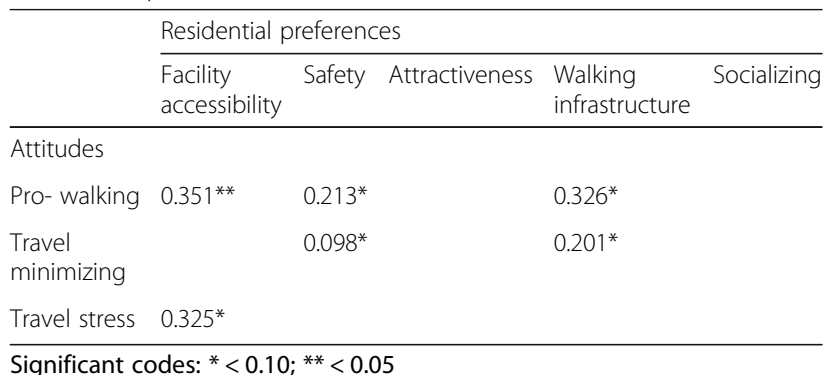

except for two factors (perceived socializing and preferred attractiveness) all other factors have different distributions between neighborhoods. Moreover, by comparing perceived factors with preferred factors, it is rather possible to see how respondents receive what they want. According to Table 8, differences between individuals' perceived neighborhood characteristics for their current residence and their neighborhood characteristic preferences do not follow a similar pattern across six neighborhoods. The results indicate that importance of preferred factors for the neighborhoods are relatively low and the residents mainly receive these factors more than what they want. However, several neighborhoods do not meet individuals' preferences for some factors very well (see Table 8). Further, we investigated the correlation between perceived and preferred factors to better understand the self-selection issue in our case studies. The results of correlational analysis show that there are relatively week positive relationships between preferences for and perception of facility accessibility, safety and attractiveness. The coefficients of the relationships were $0.115,0.214$ and 0.324 at the 0.05 level of significance. It is noted that the associations between other factors were not significant. The aforementioned evidence weakens this assumption that the respondents are self-selecting into their preferred neighborhoods. The analyses in next sections show how the explanatory variables are related to different types of walking.

\subsection{Multivariate analysis}

Multivariate models were developed to analyze the relationships between the built environment factors and utilitarian walking, hedonic walking, controlling for neighborhood preferences, attitudinal factor and sociodemographic characteristics.

In this study, we used negative binomial regression instead of ordinary least squares regression to avoid the possibly biased results. Ordinary least squares regression requires that model residuals have a normal distribution, while our walking behavior data are skewed to the left with a great deviation from the normality assumption. In this situation, according to the non-negative count data of walking trips, we compared Poisson regression and 
Table 8 Average walking frequencies, explanatory factors and p-values for associated ANOVA across neighborhoods

\begin{tabular}{|c|c|c|c|c|c|c|c|}
\hline \multirow[t]{2}{*}{ Variables } & \multicolumn{6}{|c|}{ Neighborhood } & \multirow{2}{*}{$\begin{array}{l}\mathrm{p}- \\
\text { value }\end{array}$} \\
\hline & $\mathrm{O} 1$ & $\mathrm{O} 2$ & SM1 & SM2 & M1 & M2 & \\
\hline \multicolumn{8}{|l|}{ Walking behavior } \\
\hline Utilitarian walking & 11.01 & 9.97 & 8.25 & 8.74 & 10.37 & 9.06 & 0.000 \\
\hline Hedonic walking & 3.01 & 3.05 & 3.21 & 2.27 & 3.77 & 1.96 & 0.000 \\
\hline \multicolumn{8}{|c|}{ Objective measures of the built environment } \\
\hline Residential density & 132 & 73.45 & 90 & 57.32 & 160 & 115 & 0.001 \\
\hline Entropy index & 0.51 & 0.40 & 0.28 & 0.35 & 0.67 & 0.30 & 0.000 \\
\hline Street density & 70.1 & 45.4 & 42.7 & 24.6 & 50.36 & 48.9 & 0.000 \\
\hline Cul-de-sac density & 623.5 & 492 & 300 & 250 & 95.8 & 18.19 & 0.004 \\
\hline Density of bus route & 7.2 & 10.1 & 12.15 & 5.3 & 8.49 & 3.8 & 0.003 \\
\hline \multicolumn{8}{|c|}{ Perceived measures of the built environment } \\
\hline Facility accessibility & 3.8 & 3.5 & 2.9 & 3.2 & 4.1 & 2.7 & 0.000 \\
\hline Safety & 3.1 & 4.1 & 2.8 & 3 & 3.3 & 3.1 & 0.002 \\
\hline Attractiveness & 2.4 & 3.2 & 2.8 & 2.9 & 4.3 & 3.3 & 0.002 \\
\hline Walking infrastructure & 2.7 & 2.6 & 3.4 & 3.6 & 3.7 & 3.1 & 0.001 \\
\hline Socializing & 4.2 & 3.9 & 2.7 & 3.1 & 2.9 & 2.8 & 0.104 \\
\hline \multicolumn{8}{|l|}{ Residential preferences } \\
\hline Facility accessibility & 2.7 & 2.8 & 2.5 & 3.1 & 3.4 & 2.6 & 0.010 \\
\hline Safety & 3 & 3.1 & 2.9 & 3 & 3 & 2.8 & 0.000 \\
\hline Attractiveness & 2.6 & 2.9 & 2.7 & 2.7 & 3.8 & 3 & 0.124 \\
\hline Walking infrastructure & 1.9 & 2.4 & 3.3 & 2.8 & 3.3 & 2.2 & 0.003 \\
\hline Socializing & 2.3 & 2.8 & 2.6 & 3.2 & 3.1 & 2.5 & 0.000 \\
\hline \multicolumn{8}{|l|}{ Attitudes factors } \\
\hline Pro-walking & 4.2 & 3.8 & 3.1 & 3 & 4.3 & 3.2 & 0.000 \\
\hline Car dependent & 2.3 & 2.5 & 3.6 & 3.4 & 3.7 & 3.8 & 0.043 \\
\hline Travel Minimizing & 3.4 & 3.3 & 2.7 & 4 & 2.5 & 3.9 & 0.001 \\
\hline Travel stress & 2.1 & 1.9 & 2.4 & 1.5 & 1.7 & 2.3 & 0.006 \\
\hline
\end{tabular}

negative binomial regression, as potential alternatives, to determine appropriate analysis technique (see [32]). For two types of walking, the significance of the $\alpha$-value justified the use of negative binomial models rather than Poisson models (Tables 9 and 10).

\subsubsection{Utilitarian walking trips}

The significant model for the frequency of utilitarian walking trips is presented in Table 9. Shay et al. [59] stated that "Pseudo- $R^{2}$ is a goodness-of-fit measure that varies between 0 and 1 , with higher values indicating a better fit of the model. More intuitively, it is the ratio of the estimated information gain from using the full model compared to the constants-only model. Thus, it estimates the additional information gained by including explanatory variables". Psuedo- $\mathrm{R}^{2}$ for the model of utilitarian walking is 0.352 . The results of the model show that two variables at the neighborhood level including entropy index and residential density significantly affect respondents' utilitarian walking behavior. Reasonably, the respondents who live in the neighborhoods with higher residential density and diversity are more likely to reach various activities within a shorter distance. As mentioned before, these results have been supported by various studies. In addition, out of the 5 perceived characteristics of the neighborhood, three are significantly associated with utilitarian walking trip frequency. According to incident rate ratios (IRR), increase in the perception of facility accessibility raises the odds of utilitarian walking trip frequency. It was predictable because increased facility accessibility may lead to a decrease in the distance between different activities, and accordingly a decrease in travel cost including time and out-of-pocket monetary expenditures. Perception of attractiveness is positively associated with the frequency of utilitarian walking. This result confirms the challenges that reaching a specific destination is the only important thing for utilitarian 
Table 9 Negative binomial model for utilitarian walking trip frequency

\begin{tabular}{|c|c|c|c|}
\hline \multirow[t]{2}{*}{ Variable } & \multicolumn{3}{|c|}{ Utilitarian walking } \\
\hline & Coef. & IRR & $P$ \\
\hline Constant & -0.153 & & 0.963 \\
\hline \multicolumn{4}{|c|}{ Objective Built environment factors } \\
\hline Entropy index & 0.214 & 1.239 & 0.001 \\
\hline Residential density & 0.194 & 1.214 & 0.000 \\
\hline \multicolumn{4}{|c|}{ Perceived Built environment factors } \\
\hline Facility accessibility & 0.601 & 1.824 & 0.000 \\
\hline Attractiveness & 0.574 & 1.775 & 0.001 \\
\hline Walking infrastructure & 0.245 & 1.278 & 0.002 \\
\hline \multicolumn{4}{|l|}{ Attitudinal factors } \\
\hline Pro- walking & 0.315 & 1.370 & 0.000 \\
\hline Car dependent & -0.247 & 0.781 & 0.001 \\
\hline Travel minimizing & 0.413 & 1.511 & 0.001 \\
\hline \multicolumn{4}{|l|}{ Socio-demographic characteristics } \\
\hline \multicolumn{4}{|l|}{ Age } \\
\hline $15-30$ years & 0.315 & 1.367 & 0.000 \\
\hline $45-65$ years & -0.218 & 0.804 & 0.000 \\
\hline Monthly household income & -0.194 & 0.824 & 0.000 \\
\hline \multicolumn{4}{|l|}{ Summary statistics } \\
\hline Number of Obs. & & 863 & \\
\hline$P($ alpha $)=0$ & & 0.000 & \\
\hline Pseudo $R^{2}$ & & 0.352 & \\
\hline
\end{tabular}

travel. Reasonably, it can be said that it is more probable that individuals firstly consider the shortest alternatives for utilitarian travel, but they do not ignore the qualities of the built environment such as attractiveness. Hence, it can be said that individuals consider psychological effects (e.g. aesthetics, comfort etc.) as one of the most important dimensions of utilitarian walking which satisfies them.

In addition, the perception of walking infrastructure positively affects the frequency of utilitarian walking trips. It is not surprising that pedestrian infrastructure such as presence of sidewalks and street lighting is associated with walking, because these can be considered an essential facility for safe walking. Sallis et al. [60] confirmed that the presence of sidewalks has a strong association with physical activity. In this regard, many previous studies supported our results (e.g. [61-64]). For example, several studies found that walking has positive association with perceptions of attractiveness, aesthetics or greenery $[65,66]$, the perceived convenience of local facilities [42, 65], and the perceptions of shops within walking distance [67]. However, perceived measures of the built environment may be somewhat variable across different studies. The implication of these results is that
Table 10 Negative binomial model for hedonic walking trip frequency

\begin{tabular}{|c|c|c|c|}
\hline \multirow[t]{2}{*}{ Variable } & \multicolumn{3}{|c|}{ Hedonic walking } \\
\hline & Coef. & $\mathrm{IRR}$ & P \\
\hline Constant & -5.138 & & 0.000 \\
\hline \multicolumn{4}{|l|}{ Objective Built environment factors } \\
\hline Entropy index & 0.163 & 1.177 & 0.003 \\
\hline \multicolumn{4}{|l|}{ Perceived Built environment factors } \\
\hline Attractiveness & 0.611 & 1.842 & 0.000 \\
\hline Safety & 0.389 & 1.475 & 0.001 \\
\hline \multicolumn{4}{|l|}{ Attitudinal factors } \\
\hline Pro-walking & 0.321 & 1.378 & 0.001 \\
\hline Car dependent & -0.479 & 0.619 & 0.000 \\
\hline Travel stress & -0.613 & 0.541 & 0.003 \\
\hline \multicolumn{4}{|l|}{ Socio-demographic characteristics } \\
\hline \multicolumn{4}{|l|}{ Age } \\
\hline $15-30$ years & 0.469 & 1.598 & 0.003 \\
\hline Over 65 years & -0.477 & 0.621 & 0.000 \\
\hline Unemployed & 0.543 & 1.721 & 0.000 \\
\hline Monthly household income & -0.295 & 0.744 & 0.000 \\
\hline \multicolumn{4}{|l|}{ Summary statistics } \\
\hline Number of Obs. & & 863 & \\
\hline$P($ alpha $)=0$ & & 0.000 & \\
\hline Pseudo $R^{2}$ & & 0.311 & \\
\hline
\end{tabular}

mixing land use, providing walking infrastructures and increasing aesthetic quality of the built environment may encourage individuals to use more walking for utilitarian purposes.

Interestingly, the model shows that none of residential preferences significantly contribute to explaining utilitarian walking. According to self-selection issue, individuals who prefer to walk may consciously choose to live in a walkable neighborhood. Thus, prior self-selection of residents into a built environment may cause walking [68]. Most of previous studies do not support our result regarding residential preferences (e.g. [43, 68, 69]). But the study of Etminani-Ghasrodasht and Ardeshiri [51] in the context of Iran showed that residential attitudes are slightly related to frequencies of non-work walking trips, as they suggested that this factor can be ignored in their context. In our view, it can be explained by this fact that in our context people mainly choose their residential area based on their financial position and property prices across different regions of city and other issues may have secondary priority.

Among attitudinal factors, individuals who prefer walking to driving, walk more to reach a specific destination. Instead, those who are dependent on car are less likely to walk frequently. Indeed, travel minimizing 
attitude increases the likelihood of utilitarian walking trip frequency.

Several socio-demographic characteristics play an important role in the frequency of utilitarian walking. Monthly income of household has a negative association with this type of walking. Comparison of age groups shows that young people tend to walk more frequently, while elder people are less likely to make utilitarian walking. Our result about age is consistent with Cao et al. [32, 43], but it is contrary to EtminaniGhasrodasht and Ardeshiri [51]. The negative association of age may be explained by mobility limitations or possibly safety concerns for elderly people. According to these diverse results, generalization of this result needs more research in different contexts.

\subsubsection{Hedonic walking trips}

In this section, negative binomial model was developed to investigate the influence of neighborhood factors on hedonic walking, controlling for residential preferences, travel attitudes and socio-demographic characteristics. Psuedo- $R^{2}$ for hedonic walking trip frequency is 0.311 . It is noted that the Psuedo- $\mathrm{R}^{2}$ of the model for hedonic walking trips is smaller than that for utilitarian walking trips. This suggests that survey more effectively captured variables that can explain utilitarian walking than variables that can explain hedonic walking.

This model reveals meaningful results which are mainly different from utilitarian walking. According to Table 10 entropy index is the only neighborhood characteristic, which significantly affects hedonic walking. In addition to improving accessibility for utilitarian walking, mixing land use can create a pedestrian-friendly environment, specifically for hedonic walking, through its influence on safety, vitality, social interaction and so on. Indeed, two perceived environmental attributes out of the five attributes are positively associated with hedonic walking. Those who perceived their neighborhoods as attractive places are more likely to make hedonic walking. This result has been identified in some previous studies on recreational walking [34, 54]. However, as mentioned earlier, what we mean by hedonic walking is somewhat different from recreational walking. This factor positively affects both utilitarian and hedonic walking, but its importance for hedonic walking is slightly more than utilitarian walking (IRR $=1.842$ and 1.775 , respectively). These differences can be explained by this view that primary motivation for utilitarian walking is to reach a destination; while for hedonic travelers, they often walk to satisfy their intrinsic desire. Thus, having an aesthetically pleasing environment can have more impacts on the intrinsic motivation. Safety as the other environmental measure is significantly related to hedonic walking. In our survey, the construct of safety was mainly about safety from crime and traffic. Previous studies have reported different results about safety [70-75]. Specifically in developing countries, the studies in Brazil [73] showed no significant relationship between safety from crime and walking for recreational walking, while results of Oyeyemi et al. [74] in Nigeria reported an important correlation between safety from crime and physical activity. Some studies have considered safety from traffic or some constructs of this factor such as availability sidewalks and separation from traffic. These studies mainly found that there are no associations between safety from traffic and recreational walking (e.g. [34, 71, 75]).This comparison reveals that perception of safety and importance of such perception is different in diverse countries.

Like utilitarian walking, residential preferences also have no contribution in explaining hedonic walking. This result confirmed that in our context, travel behavior does not play a dominant role when people are selecting their residential location. The results also demonstrate that this type of walking is influenced by attitudinal factors and socio-demographics. In a reasonable consequence, people with pro-walking attitude tend to do more hedonic walking. In addition, increase in the perception of car dependent and travel stress significantly lower the odds of this type of walking. These results show that attitudinal factors differently affect two types of walking. For example, while travel stress does not contribute in explaining utilitarian walking, it has an important influence on hedonic walking. It supports this view that one of the principal purposes of those who make hedonic walking is to reach a state of relaxation.

Three socio-demographic characteristics are significant in the model of hedonic walking trip frequency. Both models of hedonic and utilitarian walking trips have two socio-demographic variables including age and monthly incomes of household in common. Like utilitarian trips, elders tend to have fewer hedonic walking trips than youths, which is likely due to the elders' limited physical ability or possibly safety concerns. The influence of unemployment status is positive for hedonic walking. This result was predictable since unemployed individuals are more likely to have more free time to travel for its own sake. Finally, similar to utilitarian trips, household income is negatively associated with hedonic walking trips. It may be due to the idea that people with higher income usually choose driving instead of walking to make travel for its own sake.

\section{Conclusion}

Walking for any purpose and with any motivation has many benefits for individuals and society. Planners and public health officials have tried to design appropriate policies to encourage walking. Generally, individuals 
walk with different degrees of motivation from purely extrinsic to completely intrinsic motivation. In this study, we exclusively identified two types of walking; and it is noted that they is only one manifestation of utilitarian walking or non-utilitarian walking.

The findings of the study reveal interesting insights into the walking behavior-built environment relations. Both types of walking are influenced by three kinds of explanatory factors, but the kind of affecting factors or their importance is somewhat different. This confirms that it is essential to be more sensitive to the motivation of trips and suggests clear policy implications: the individuals' reactions toward policies intended to increase walking frequency depend partly on the utility for walking because different factors contribute to explaining utilitarian and hedonic walking differently. In order to develop the subject, we suggest that future research try to measure the relative weights that people assign to different components of utility for each travel and then analyze the travel behavior-built environment relations.

The multivariate analyses showed that if we aim to increase walking frequency, it is imperative to change both built environment characteristics and attitudinal factors. As for the variables associated with utilitarian and hedonic walking, the perception of facility accessibility and walking infrastructure are related to utilitarian walking, and safety is related to hedonic walking. The perceived attractiveness is also positively correlated with both types of walking. It is more likely that this factor affects walking through psychological effects. Theoretically, attractiveness does not directly affect travel distance, but this factor plays an important role in explaining utilitarian travel. Therefore, this result challenges this assumption that built environment affects utilitarian travel only through shortening travel time and distance. Future research can investigate this issue for some specific utilitarian destination or activities separately. Some land use and transportation implications of our findings are that increasing facility accessibility through mixed land use, interconnected street network, infill development, investment in walking infrastructure, and making an attractive neighborhood through urban design, natural elements, park and open space etc. can induce people to walk more.

Our findings about residential preferences are mainly inconsistent with the majority of previous studies. It is interesting that another study conducted in Shiraz, Iran reported a weak association of this factor with travel behavior [51]. This may be due to low priority of travel behavior issue compared to other factors such as the price of housing when people aim to choose their residential areas. Future research may be willing to reveal more insights into residential self-selection in developing countries.

This study like many others may have a number of limitations, which should be considered in order not to underestimate or overstate the results. First, this paper considered only perceived neighborhood characteristics, residential preferences, travel attitudes, and sociodemographic characteristics as explanatory variables, while there are other variables such as objective variables of the built environment, lifestyle, and personality, etc. that may reveal more insights into the results. Second, we selected only four destinations for non-work walking trips and four activities as hedonic walking trips. Hence, these trips may not be a comprehensive manifestation for each type of walking. Finally, this paper, like many other researches, did not model the interrelationship between explanatory variables, while walking behavior may also be influenced by the variables indirectly. Accordingly, future research can be conducted to consider the mentioned issues.

\section{Endnotes}

${ }^{1}$ Utilitarian type of walking has various labels such as active travel, non-motorized travel, transport related physical activity, and destination-oriented walking. Hedonic type of walking also has several labels, including walking for its own sake, undirected walking, walking for leisure and so on. But, it is worth noting that there are noticeable differences between these terms in different studies. We adopted our terms based on the categories of Mokhtarian et al. [18]. She reviewing a number of theories of motivation, distinguishes between extrinsic (instrumental, utilitarian, functional) and intrinsic (autotelic, hedonic, experiential) motivations of travel.

${ }^{2}$ In original dataset, we have 863 respondents and 30 variables (15 preferences and 15 perceptions), but for extracting perception and residential preference factors, we produced a new dataset with 1726 respondents and 15 variables by combining all responses relating to perception and residential preference statements, and then factor analysis were ran on the new dataset.

Authors' contributions

All authors read and approved the final manuscript.

\section{Publisher's Note}

Springer Nature remains neutral with regard to jurisdictional claims in published maps and institutional affiliations.

\section{Author details \\ ${ }^{1}$ Faculty of Architecture and Environmental design, Iran University of Science and Technology (IUST), Narmak, Tehran 1684613114, Iran. ${ }^{2}$ Department of \\ Transport, Health, Safety at Ifsttar, 69675 Bron Cedex, France.}

Received: 22 September 2017 Accepted: 5 April 2018

Published online: 25 May 2018

\section{References}

1. Mokhtarian PL, Salomon I, Redmond L (2001) Understanding the demand for travel: It's not purely 'derived'. Innovation: The European Journal of Social Science Research 14(4):355-380

2. Mokhtarian PL, Salomon I (2001) How derived is the demand for travel? Some conceptual and measurement considerations. Transp Res A 35(8):695-719 
3. Papon, F., and Meissonnier, J. (2013). Mind your travel! Motivation, time use, and intent: three factors of travel to be investigated. Paper presented at the 13th World Conference on Transport Research, Rio de Janeiro, Brazil

4. Susilo, Y. O., Lyons, G., Jain, J., and Atkins, S. (2012) Rail passengers' time use and utility assessment: 2010 findings from Great Britain with multivariate analysis. Paper no. 12-1343 presented at the 91st Annual Meeting of the Transportation Research Board, Washington, DC

5. Isfahan university of technology (2013) Comprehensive transportation plan of Isfahan, Isfahan municipality, deputy of traffic and transportation, Isfahan, Iran

6. Talen E, Koschinsky J (2013) The walkable neighborhood: a literature review. International Journal of Sustainable Land Use and Urban Planning 1(1):42-63

7. Forsyth A (2015) What is a walkable place? The walkability debate in urban design. Urban Design International 20(4):274-292

8. Frank LD, Kerr J, Sallis JF, Miles R, Chapman J (2008) A hierarchy of sociodemographic and environmental correlates of walking and obesity. Prev Med 47(2):172-178

9. Doyle $S$ et al (2006) Active community environments and health: the relationship of walkable and safe communities to individual health. J Am Plan Assoc 72(1):19-31

10. Durand CP et al (2011) A systematic review of built environment factors related to physical activity and obesity risk: implications for smart growth urban planning. Obes Rev 12(5):e173-e182

11. Yang Y (2016) A dynamic framework on travel mode choice focusing on utilitarian walking based on the integration of current knowledge. J Transp Health 3(3):336-345

12. Leyden KM (2003) Social capital and the built environment: the importance of walkable neighborhoods. Am J Public Health 93(9):1546-1551

13. Doescher et al (2014) The built environment and utilitarian walking in small U.S. towns. Prev Med 69:80-86

14. Saelens BE, Sallis JF, Frank LC (2003) Environmental correlates of walking and cycling: findings from the transportation, urban design, and planning literature. Ann Behav Med 25(2):80-91

15. Guo J, Bhat C, Copperman R (2007) Effect of the built environment on motorized and nonmotorized trip making: substitutive, complementary, or synergistic? Transportation Research Record: Journal of the Transportation Research Board 2010(1):1-11

16. Rutt CD, Coleman KJ (2005) The impact of the built environment on walking as a leisure-time activity along the US/Mexico border. J Phys Act Health 3:257-271

17. Lee C, Moudon AV (2004) Physical activity and environment research in the health field: implication for urban and transportation planning practice and research. J Planning Literature 19(2):147-181

18. Mokhtarian PL, Salomon I, Singer ME (2015) What moves us? An interdisciplinary exploration of reasons for traveling. Transport Reviews: A Transnational Transdisciplinary Journal 35(3):250-274

19. Hupkes $G$ (1982) The law of constant travel time and trip-rates. Futures 14 38-46

20. Diana M (2008) Making the 'primary utility of travel' concept operational: a measurement model for the assessment of the intrinsic utility of reported trips. Transp Res A 42(3):455-474

21. Redmond LS, Mokhtarian PL (2001) The positive utility of the commute: modeling ideal commute time and relative desired commute amount. Transportation 28:179-205

22. Richardson AJ (2003) Some evidence of travelers with zero value of time. Transp Res Rec 1854:107-113

23. Pa'ez A, Whalen K (2010) Enjoyment of commute: a comparison of different transportation modes. Transp Res A 44(7):537-549

24. Gottholmseder G, Nowotny K, Pruckner GJ, Theurl E (2009) Stress perception and commuting. Health Econ 18:559-576

25. Lin W (2012) Wasting time? The differentiation of travel time in urban transport. Environ Plan A 44(10):2477-2492

26. Gripsrud M, Hjorthol R (2012) Working on the train: from 'dead time' to productive and vital time. Transportation 39:941-956

27. Abou-Zeid M, Witter R, Bierlaire M, Kaufmann V, Ben-Akiva M (2012) Happiness and travel mode switching: findings from a Swiss public transportation experiment. Transp Policy 19(1):93-104

28. Ettema D, Garling T, Eriksson L, Friman M, Olsson LE, Fujii S (2011) Satisfaction with travel and subjective well-being: development and test of a measurement tool. Transp Res F 14:167-175

29. Friman M, Fujii S, Ettema D, Garling T, Olsson LE (2013) Psychometric analysis of the satisfaction with travel scale. Transp Res A 48:132-145
30. Russell M, Mokhtarian PL (2015) How real is a reported desire to travel for its own sake? Exploring the 'teleportation' concept in travel behaviour research. Transportation 42:333-345

31. Boarnet MG, Crane R (2001) The influence of land use on travel behavior: specification and estimation strategies. Transp Res A 35(9):823-845

32. Cao X, Handy SL, Mokhtarian PL (2006) The influences of the built environment and residential self-selection on pedestrian behavior: evidence from Austin, TX. Transportation 33(1):1-20

33. Giles-Corti B, Donovan RJ (2002) Socio-economic status differences in recreational physical activity levels and real and perceived access to a supportive physical environment. Prev Med 35(6):601-611

34. Saelens BE, Handy SL (2008) Built environment correlates of walking: a review. Med Sci Sports Exerc 40(Suppl. 7):S550

35. Christiansen LB et al (2016) International comparisons of the associations between objective measures of the built environment and transport-related walking and and cycling: IPEN adult study. J Transp Health 3(4):467-478

36. Clark AF, Scott DM, Yiannakoulias N (2014) Examining the relationship between active travel, weather, and the built environment: a multilevel approach using a GPS-enhanced dataset. Transportation 41(2):325-338

37. Frank LD, Saelens BE, Powell KE, Chapman JE (2007) Stepping towards causation: Do built environments or neighborhood and travel preferences explain physical activity, driving, and obesity? Soc Sci Med 65(9):1898-1914

38. Lovasi GS, Schwartz-Soicher O, Neckerman KM, Konty K, Kerker B, Quinn J et al (2013) Aesthetic amenities and safety hazards associated with walking and bicycling for transportation in New York City. Ann Behav Med 45(1):76-85

39. Van Dyck D et al (2010) Neighborhood SES and walkability are related to physical activity behavior in Belgian adults. Prev Med 50:S74-S79

40. Craig CL, Brownson RC, Cragg SE, Dunn AL (2002) Exploring the effect of the environment on physical activity: a study examining walking to work. Am J Prev Med 23(2):36-43

41. Wilbur J, Chandler PJ, Dancy B, Lee H (2003) Correlates of physical activity in urban Midwestern African-American women. Am J Prev Med 25(3 Suppl 1):45-52

42. Humpel N, Owen N, Iverson D, Leslie E, Bauman A (2004) Perceived environment attributes, residential location, and walking for particular purposes. Am J Prev Med 26(2):119-125

43. Cao X, Mokhtarian PL, Handy SL (2009) The relationship between the built environment and nonwork travel: a case study of northern California. Transp Res A 43(5):548-559

44. Cao X, Mokhtarian PL, Handy SL (2009) No particular place to go: an empirical analysis of travel for the sake of travel. Environ Behav 41(2):233-257

45. Panter J, Griffin S, Ogilvie D (2014) Active commuting and perceptions of the route environment: a longitudinal analysis. Prev Med 67:134-140

46. Foster S, Giles-Corti B, \& Knuiman M (2014) Does fear of crime discourage walkers? A social-ecological exploration of fear as a deterrent to walking. Environment and Behavior, 46(6), 698-717.

47. Hoehner CM, Brennan Ramirez LK, Elliott MB, Handy SL, Brownson RC (2005) Perceived and objective environmental measures and physical activity among urban adults. Am J Prev Med 28(2):105-116

48. Munshi T (2016) Built environment and mode choice relationship for commute travel in the city of Rajkot, India. Transport Res Part D 44:239-253

49. Zacharias J (2005) Non-motorized transportation in four shanghai districts. Int Plan Stud 10(3-4):323-340

50. Pan H, Shen Q, Zhang M (2009) Influence of urban form on travel behaviour in four neighbourhoods of Shanghai. Urban Stud 46(2):275-294

51. Etminani Ghasrodashti R, Ardeshiri M (2016) The impacts of built environment on home-based work and non-work trips: an empirical study from Irans. Transp Res A 85:196-205

52. Etminani Ghasrodashti R, Ardeshiri M (2016) Modeling travel behavior by the structural relationships between lifestyle, built environment and nonworking trips. Transp Res A 78:506-518

53. Handy SL (1996) Urban form and pedestrian choices: a study of Austin neighborhoods. Transp Res Rec 1552:135-144

54. Sugiyama T et al (2014) Perceived neighbourhood environmental attributes associated with adults' recreational walking: IPEN adult study in 12 countries. Health Place 28:22-30

55. Isfahan Municipality Official Website, (2017) <http://new.isfahan.ir/Index aspx?tempname $=\mid$ sfahan95\&lang $=1 \&$ sub $=0>$ (accessed 11 Mar 17)

56. Naghshe-Jahan Pars Consultants (2012) The revision of detailed plan of Isfahan, Isfahan municipality, deputy of architecture and urban planning, Isfahan, Iran 
57. Ding C, Wang Y, Tang T, Mishra S, \& Liu C (2016) Joint analysis of the spatial impacts of built environment on car ownership and travel mode choice. Transportation Research Part D: Transport and Environment.

58. Ory D, Mokhtarian P (2009) Modeling the structural relationships among short-distance travel amounts, perceptions, affections, and desires. Transp Res Part A 43:26-43

59. Shay E, Fan Y, Rodriguez DA, Khattak AJ (2006) Drive or walk? Utilitarian trips within a neo-traditional neighborhood. Transp Res Rec 1985:154-161

60. Sallis JF, Frank LD, Saelens BE, Kraft MK (2004) Active transportation and physical activity: opportunities for collaboration on transportation and public health research. Transp Res A Policy Pract 38(4):249-268

61. Clifton KJ, Dill J (2005) Women's travel behavior and land use: will new styles of neighborhoods lead to more women walking? In: TRB research on Women's issues in transportation, transportation research record, pp 89-99

62. Lee C, Moudon AV (2006) Correlates of walking for transportation or recreation purposes. J Phys Act Health 3:77-98

63. Spence JC, Plotnikoff RC, Rovniak LS, Martin Ginis KA, Rodgers W, Lear SA (2006) Perceived neighbourhood correlates of walking among participants visiting the Canada on the move website. Can J Public Health 97:36-40

64. McMillan TE (2005) Urban form and a child's trip to school: the current literature and a framework for future research. J Plann Lit 19:440-456

65. Ball K, Bauman A, Leslie E, Owen N (2001) Perceived environmental aesthetics and convenience and company are associated with walking for exercise among Australian adults. Prev Med 33(5):434-440

66. Ellaway A, Macintyre S, Bonnefoy X (2005) Graffiti, greenery, and obesity in adults: secondary analysis of European cross sectional survey. BMJ 331(7517):611-612

67. Foster C, Hillsdon M (2004) Changing the environment to promote health enhancing physical activity. J Sports Sci 22(8):755-769

68. Cao X (2014) Examining the impacts of neighborhood design and residential self-selection on active travel: a methodological assessment. Urban Geography 36(2):1-20

69. Van Acker V, Mokhtarian P, Witlox F (2014) Car availability explained by the structural relationships between lifestyles, residential location, and underlying residential and travel attitudes. Transp Policy 35:88-99

70. Owen N, Humpel N, Leslie E, Bauman A, Sallis JF (2004) Understanding environmental influences on walking : review and research agenda. Am J Prev Med 27:67-76

71. Sugiyama T, Neuhaus M, Cole R, Giles-Corti B, Owen N (2012) Destination and route attributes associated with adults' walking: a review. Med Sc Sports Exerc 44:1275-1286

72. Inoue S, Ohya Y, Odagiri Y, Takamiya T, Kamada M, Okada S, Oka K, Kitabatake Y, Nakaya T et al (2011) Perceived neighborhood environment and walking for specific purposes among elderly Japanese. J Epidemiol 21 481-490

73. Gomes GA, Reis RS, Parra DC, Ribeiro I, Hino AA, Hallal PC, Malta DC, Brownson RC (2011) Walking for leisure among adults from three Brazilian cities and its association with perceived environment attributes and personal factors. Int J Behav Nutr Phys Act 8:111

74. Oyeyemi AL, Adegoke BO, Sallis JF, Oyeyemi AY, DeBourdeaudhuij I (2012) Perceived crime and traffic safety is related to physical activity among adults in Nigeria. BMC Public Health 12:294

75. Kramer D, Maas J, Wingen M, Kunst AE (2013) Neighbourhood safety and leisure-time physical activity among Dutch adults: a multilevel perspective. Int J Behav Nutr Phys Act 10:11

\section{Submit your manuscript to a SpringerOpen ${ }^{\circ}$ journal and benefit from:}

- Convenient online submission

Rigorous peer review

- Open access: articles freely available online

- High visibility within the field

Retaining the copyright to your article

Submit your next manuscript at $\boldsymbol{\nabla}$ springeropen.com 